\title{
Social, Cultural and Natural Factors in Formation of the Tatars Culinary Vocabulary
}

\author{
Raushaniya Sagdatzyanovna Nurmukhametova \\ Madina Rashidovna Sattarova
}

Kazan Federal University, 18 Kremlevskaya st., 18, Kazan, 420008, Russia

\author{
Doi:10.5901/mjss.2015.v6n6s2p55
}

\section{Abstract}

The human life, associated with food, is varied and complex. The food is relevant and valuable to any people at ay stages of its development, therefore in each language the lexical-thematic group "food" presents a significant number of lexical items, many of which have a long history in the language. Due to the natural habitat of the people, its main historical occupations, the cultural and historical development of food, related national cuisine is one of the most specific areas of the culture, which is reflected in its linguistic scope. Main factors determining the nature of traditional dish are the way of life of the people, economy, religion, natural resources, climate, geography of the country, neighboring peoples, etc. National Tatar cuisine was influenced by external factors and formed to provide the human body with all of the nutrients to promote effective adaptation to the environmental conditions. The article discusses the food names of the Tatar language on the background of those natural conditions that influenced the formation of eating behavior of the ethnic group. Studying the food vocabulary leads to the conclusion that each language is an integral part of the life of any nation and the history of a native speakers. Such research is determined by the need of modern linguistics in the study of the circumstances and factors of the formation of material and spiritual culture of a nation.

Keywords: Tatar language, food, social and cultural factors, climate conditions, food culture.

\section{Introduction}

In modern conditions of globalization of a society, there is an increasing interest in the study of language in its relationship with the phenomenon of national culture. As the most important level of a language system stores vocabulary transmits ethnic and cultural features from generation to generation. Therefore, the main aim of linguistic studies of cultural direction is devoted to the study of the lexicon that has information about the national peculiarities of perception of the world.

A diverse and multifaceted vocabulary of the Tatar people includes a specific unit group - a culinary vocabulary. It is unique in that, through the familiarity with it, a person's world is broaden, generating interest in the culture of the people. More than in other areas of food and food vocabulary preserve traditional features, related ideas about the national identity of the people. Therefore the scientists connect the national culture and ethnic group study with the study of the lexicon that has information about the national peculiarities of perception of the world by a nation, reflecting the history, life and customs of a people.

The aim of this article is to study the effect of external factors on the formation and functioning of the food vocabulary of the Tatar language. In accordance with the aim of the study the following tasks are suggested: to identify the range of natural and social factors that influenced the culinary vocabulary of the Tatar language; to describe the influence of climatic conditions on the choosing food by Tatar people; to define the role and place of religious outlook on food in the ethnic group; to describe external influences on food culture.

\section{A Review of the Literature}

In the Tatar linguistics, there are works devoted to the description of individual words and groups of words. Some layers of the vocabulary of the Tatar language (terminology, onomastics, phraseology, dialectology, etc.) are also well studied. In recent years more attention is paid to the vocabulary of material and spiritual culture, ethnic and cultural vocabulary of the Tatar language; lexical features of the language of the Tatar Diaspora (Zamaletdinov and Nurmukhametova, 2012; Nurmukhametova and Sattarova, 2013; Nurmukhametova et al., 2014; Yusupova, 2013; Denmukhametova and Yusupova, 2011). It is also an important issue of using the information and communication media in teaching vocabulary 
of the Tatar language (Fatkhullova K. S. et al, 2013).

The food names in the Tatar language covered in the scientific literature in some extent, they are found in various dictionaries. The rich factual material of dictionaries of the 19th century has been studied and evaluated by A.Sh. Yusupova (Yusupova, 2014 and Yusupova, 2008).

A systematic study of the food names is reflected in the monograph "The food Names in the Tatar language" (Khajrutdinova, 1993); in the book "Vocabulary of Tatar folk Proverbs" the legacy names in the thematic group 'food' are examined (Mugtasimova, 2005). The scientific work "Vocabulary of food and folk traditions" (Bayazitova, 2007) is devoted to the systematization of dialect and literary food names in connection with national traditions. In the Appendix of the monograph "Theoretical and applied aspects of the Tatar cultural linguistics" (Zamaletdinov, 2009) R.R. Zalaletdinov provides a brief ethnic and cultural dictionary, giving a linguistic description of some cultural linguistics units of the thematic group 'food'. In the monograph by F. Kh. Tarasova "Proverbs with the 'food' component in the Tatar, Russian and English languages" the 'food code' is discussed on the material of different structured languages (Tarasova, 2012). The scientific reserch "Ethnic and cultural dictionary of the Tatar language vocabulary of material culture" (Zamaletdinov and Nurmukhametova, 2012) is dedicated to the description of linguistic features of the names of 30 dishes of Tatar cuisine. In articles R.S. Nurmuhametova traces the development of the culinary vocabulary of the Tatar language (Nurmukhametova, 2013 and Nurmukhametova, 2014), etc.

\section{Methods and Materials}

Methodological base of the research is the combination of a number of general scientific and private linguistic methods. The material of the research imposed the necessity of highlighting the systemic and structural approach, which allows tracing the mechanisms of formation and functioning of the culinary vocabulary of the Tatar language. The historical approach of the study gives the opportunity to represent both separate and entire groups' history of food names. Descriptive method was used in the collection and systematization of materials on the research topic. We carried out a systematic and comprehensive analysis of the lexical material using lexical and semantic methods. Comparative and contrastive methods were used in the study of borrowed words. We consider the culinary vocabulary of the Tatar language as a unified historical and cultural phenomenon. For the convenience of scientific analysis they are investigated due to their chronological, cultural, historical, ethnic and social belonging, and relevance to the conceptual sphere "food". From our point of view as well as the research theory these chosen methods are the best for such investigations.

The research is based on lexicographic sources, namely the Tatar dictionaries of the 20-21 centuries. For the first time as an illustrative material we use the works of Karl Fuchs, Kayum Nasiri. The famous ethnographer, historian, archaeologist, Professor of the Kazan Imperial University Karl Fuchs (1776-1846) tenderly treated the rituals, the holidays, the customs of the Tatars, carefully studied and collected materials about the everyday life of the people. In his famous book "Kazan Tatars in statistical and ethnographical relations" (1844), Karl Fuchs gave a detailed description of the life of the Tatars, including culinary traditions. In this work many traditional food names of the Tartars of that time have been given (Fuchs, 1991). His observations are very valuable for studying the material culture of the Tatars. The famous Tatar scientist, ethnographer, writer and educator of the 19th century Kayum Nasiri (1825-1902) also paid much attention to the study of the history of the region, the Tatar people's life, the folklore and ethnographic heritage. In the work by K. Nasiri "Materials on the Tatar Ethnography" there is a unit devoted to the food of the Tartars (Nasiri, 2005).

\section{The Results and Discussion}

Despite plenty of research, this work is also relevant owing to the names of the food of the Tatar language are considered in this work against the background of environmental factors, in particular the natural environment, which has influenced the food culture of the people. A severe and cold climate was a reason to the emergence of a large number of hot dishes in the cuisine of the Tatars. Hot soups are a prime example of this circumstance. Ash ('soup') Tatars cooked in meat broth (itle ash), in milk (sutle ash), in water (kisir ash), etc. adding different dressings: tukmach ('noodles'), salma ('flour product in the form of shells'), chumar (dumplings), umach (dough balls that are placed in the soup like dumplings). "The Tatar peasant food: ... for a lunch salma consisting of crumbling dough with lamb fat" (Fuchs, 1991). Soup with different cereals Tatars called uyra. Now it is just called as yarmaly ash ('soup with a grain'). According to K. Nasiri, it was of a great importance to the Tatars the different soups in Tatar cuisine: "... uyra is grain soup. Grain can be very different. For example, if you cook a chicken, broth is seasoned the with salma or rice. As a result we have the rice uyra, above all when iyra is diluted with milk, as is often done" (Nasiri, 2005).

Another feature of the food culture of the Tatars is that they are big fans of tea, mainly due to climate conditions. 
Tea for the Tatars is not ritual and ceremonial in nature, as in eastern nations. However, this unique feature of the Tatar cuisine is reflected in theTatar proverbs (Isanbet, 2010): Chei yany - gaile zhany - 'There is the whole family at the tea table'; Chei yanynda suz chyga - 'At the tea table there is a speech'; Ber chinayak cheinen kyryk yel khatere bar - 'You will long remember a person who treat you tea'; Chey chinayagy uch bulir - the tea traditions of the Tatars: you should drink at least three cups, i.e. the Tatars drink tea for long, talking slowly, discussing a business; Ach karinga kati chei the tea party should be accompanied by eating, so the Tatars have so many pastry dishes that are served with tea and call them chei riziklari. K. Fuchs assessed rightly "The main dish of the Tatars is tea, which ought to be drunk at least four cups."

It is a well-known fact that there are a lot of traditional high-calorie and fat food in countries with cold climate because such kinds of foods help to warm up even on the coldest day. Tatar cuisine can boasts with such dishes. "Tatars unusually like to eat a sweet and greasy dish"; "The dominant food of the Tatars is floury and oily, especially in rich families, where they consume different kinds of butter and lamination biscuits, dumplings, fat noodles, cream (clotted cream), etc. in a great amount" (Fuchs, 1991). This is manifested in the fact that among the Tatar food there are a lot of fried dishes (meat, flour products, potatoes, etc.) and fat meal (meat, butter, animal fat, etc.). For example, meat of goose, duck, any roasted meat, kazilik ('traditional sausage made from horse meat'), etc. Flour products - bavyrsak, peremech, sumsa, chakchak, koimak, belesh, etc. - are fried in oil or greased after baking. "Early in the morning they drink tea and eat little round bun with beef, called peremech". "In the afternoon for lunch they serve: 3) a roast goose or a duck with potatoes; ... 6) tea, with small butter loaf, which is in the size of a hazelnut, called bavyrsak". "Then put on the table clotted cream, (the thick, boiled cream) raspberry pastila (jam) and thin fried tortillas" (Fuchs, 1991).

An example of the effect of natural resources on the traditional Tatar cuisine is the use of "natural food as dried and processed berries, nuts, wild plants (nettle, sorrel, etc.) as well as a game. In early spring Tartars prepare kisir ash meatless (vegetarian) Tatar soup made of wild edible plants, sometimes seasoned with egg: kichitkan ashy (nettle soup), kuzgalak ashy (sorrel soup), baltyrgan ashy (soup with cow parsnip), etc. They make kainatma ('jam') from berries, and it is like pastila, confiture; make a filling for sweet cakes, and served kainatma with tea. "At the end of a long dinner, the hostess brought.... a cake made from different nuts and fruit with honey, butter and flour" (Fuchs, 1991). "They bake an apple pie. This pie does look like bekken and it resembles the same kind of the Russian pie. Mostly it is round, the top is sprinkled with sugar. The food is delicious. Such kind of pies is usually made from apple or strawberry pastila" (Nasiri, 2005). A pie is a flour product, slathered on top of grated fruit or fruit filling. It is made with a filling as pastila or fruit. Kakly pashtet is a pate with a jam. In Tatar dialects national dish chakchak is also called cactush. This word consists of two words: kak ('pastille') + tush (kernel). The most common "forest food" is mushroom was not popular with the Tatars, only "The Tatars-Mishars, who live near a forest, eat mushroom, that why it is not typical for the Kazan Tatars" (Mukhamedova).

A lack of natural resources can reflect the peculiarities of the traditional cuisine. For example, the shortage of fuel played an important role in the formation of cooking features of the Tatars: many dishes of Tatar cuisine are cooked and baked in an oven; thereby the house is heated in winter. In summer light soups and milk soup are prepared, and there is no special need to heat a house.

Some of the dishes appeared in connection with traditional activities and way of life of the people. People, who were engaged in cattle breeding and poultry farming, have many dairy products, varieties of meat. As noted by K. Fuchs, for the commoners meat was a luxury and farmers could afford meat rarely and eat it only on special occasions: "On holidays they have lamb. In celebration, called Jien and wedding parties they eat horse meat" (Fuchs, 1991).

Earlier the Tatars had no special devices where they could store milk and meat at low temperatures. So people have learned to ripen the milk, to use salt for salting meat, for preventing spoilage. Also they learnt to dry and cure meat: kaklagan kaz ('dried goose'); kazilik ('homemade sausage' (smoked or cured)).

The following dairy products of the Tatars are well-known: thick sour cream, kaimak ('clotted cream'); peshken kaimak ('baked clotted cream'). "At 6 p.m. they drink tea with cream and butter pies again, like in the morning"; "nowhere you cannot find such a delicious and rich cream, like Tatars cream, especially clotted cream and boiled cream, thick as foam". Katyk is sour milk, national sort of kefir made from baked milk with the addition of substances: "For lunch they served the table: 1) dumplings with beef and sour milk (meaning: katyk)"; "The Tatar peasant's food... is sour milk in summer" (Fuchs, 1991). Eremchek is cottage cheese. Having dried up eremchek, they received a kort Ikurt, a kind of cheese. Dried red curd was used as a filling for pies, cakes and gubadiya. "Gubadiya is round like belesh, but for the filling is differ. The meat is not cut; it is chopped finely with a chopper. Kurt ('dried cottage cheese') is put on meat, the next layer is rubbed boiled eggs, the next one is butter" (Nasiri, 2005).

Agriculture contributed to the emergence of pastry dishes (some of them were already mentioned above) and dishes from different cereals and flour: bolamyk (mash), botka (porridge), talkan (oatmeal), etc. "The meal of the Tatar 
peasants are: in the morning rye flour, boiled in salted water (bolamyk or talkan)" (Fuchs, 1991). In some dialects of the Tatar language bolamyk is used in the meaning of "mashed potato". K. Nasiri wrote "Sometimes they make well-known porridge. But the porridge is basically food of the villagers" " (Nasiri, 2005). Porridge was made from different cereals and it was considered as an obligatory dish at various celebrations: the birth of a child, building a house, farming, ranching, etc.

Growing of various vegetables in a garden have also enriched the cuisine of the Tatars. Basically, they grew potatoes, pumpkins, later they began to grow cabbage, cucumbers, etc. K. Fuchs wrote, "In the gardens of the hardworking Tatars everything is planted in abundance: potatoes, onions, beets, carrots and cabbage; all of these vegetables they store for winter." In many Tatar dishes the basic components is potato: uchpochmak ('triangle'), belesh, kistibyi, bekken, etc. At the same time a pumpkin, a carrot, a cabbage are not less popular. K.Nasiri wrote "...the filling can be different. It can be a baked pumpkin. For instance, the pumpkin is cut into small pieces and mixed with rice, then butter is added butter and the bekken is baked. Before serving, the bekken is greased with oil. It makes the bekken delicious. Bekken can be also made from carrots." Now gardening is strongly developed by Tatars, the vegetables are prepared for the future: you can taste fermented, salted, pickled vegetables.

Religion as part of life of the people is also reflected in traditional cuisine, affecting the diet and culinary customs. Tatar Muslims usually eat beef, horse meat, lamb, meat poultry. Islam forbids consumption of pork and meat of wild birds.

In complex analysis of food preferences the importance for Muslim Tatars of concepts of Halal (Arabic: حلال halāl, 'permissible') is extremely important. The Halal food simply means permitted or lawful. So when we speak about halal foods it means any foods that are allowed to be eaten according to Islamic Sharia law. It primarily ensures the security and benefit for human health. Generally Halal food means clean both in material and spiritual terms without harmful to human health contaminants of the product. First of all the concept of 'Halal' refers to meat dishes, implying animals slaughtered in the name of Allah and permitted by the Quran. The Tatars have always meat meal in their cuisine, therefore, with the adoption of Islam, meat was perceived completely by religion. For Tatars favorite meat dishes are azu, kazilik, katlama, kyzdyrma, tutirgan tawik, tutirma, uchpochmak, peremech and other dish closely associated with concept 'Halal'.

Opposite to Halal is 'Haram' (Arabic: حَرَّarām) an Arabic term meaning sinful. Haram in Islamic jurisprudence is used to refer to any act that is forbidden by Allah. Haram defines anything that is prohibited according to the Islamic law. Meats that are considered Haram, such as pork, meat of animals killed by current or by strangulation, dead animals, blood, gland of internal secretion, gall bladder, meat predatory birds and animals, and products made from them. On the basis of these lexical units, it should be emphasized that for the Muslim Tatars food culture primarily relates to the concepts of lawful and unlawful.

Another group of food is seafood. As more Tatar settlements are located near beaches and coasts, a lexical unit alabuga (bass), balik (fish), zhaen (sheatfish), kara balik (lin), korban balik (fish bream), kizil kanat (rudd), kirpi balik (beluga), opti (tench), soleyman balik (salmon), taban balik (European carp, crucian carp), tashbash (gudgeon), chabac (roach), churtan (pike), chuge (sterlet), shirtlaka (ruff), etc. are widely used in the modern Tatar language. Through crosscultural contacts, in the lexicon of the Tatars such units as sardines, squid, flounder, shrimp, mackerel, salmon, mackerel, tuna, trout, etc. are appeared.

There are various beliefs regarding the unlawfulness of some animal meat or seafood. In our opinion, these beliefs are connected with pre-Islamic period. For example, there's a people's belief that rabbit meat, pile should not be eaten by a man. According to the canons of Islam these beliefs are refuted.

In the Tatar language, such expressions as the post (fasting month of Ramadan) must be noted in the description of the food culture. The word diet is the consumption of certain products in connection with the treatment of certain diseases restriction.

During the post nutritious foods is eaten in the morning and after sunset in the evening they drink liquids as water and tea and eat light foods. The concept of diet is unchanged and related to a dietary pattern. It may be associated with the time of supply, degree of salinity, sweetness, greasy, fat, etc.

In recent years, vegetarianism is close to Tatars. Concepts of diet and vegetarianism are not synonyms in the Tatar language, because of this phenomenon is a result of the influence of foreign culture. It should be noted that in the last decades the tradition and food culture have some outside influence. For example, in the speech of the younger generation such expressions as Coca-Cola, pizza, roll, sushi, hot dog, etc. are active. It can gradually be forced out of usage such names as gubadiya, belesh, sutle chei (tea with milk), tokmachly ash (noodle soup), etc. 


\section{Conclusion}

Culinary heritage, got the Tatars from their ancestors, includes a variety of soups - tokmachly ash (noodle soup), umach (dough balls that are placed in the soup like dumplings), chumar (dumplings), salma (dumplings in the form of shells), etc.; dairy products - kaimak (cream), sour cream (a kind of national fermented milk product), the kort (dried red cottage cheese), eremchek (cottage cheese), etc.; meat dishes - kazilik (homemade dried sausage), kaklagan kaz (goose jerky), etc.; plant food - botka (porridge), bolamik (puree), talkan (oatmeal), etc.; pastry with filling and without filling uchpochmak (triangle) belesh (a national pie), koimak (thick pancakes), kistibiy (a pie stuffed with potato), bavyrsak (butter and flour product, made as balls and fried in oil), peremech (national food made of dough and minced meat, etc.), sweet pastry treats for tea - cakes, pies, chakchak, etc.

Review of the materials on the traditional food of the Tartars confirm the idea that severe climate, conditions of nature and farming contributed to the formation of rational type of a national food. This study showed that the food traditions of the Tatars have developed over many centuries, and many of them have retained their identity to the present day.

Because of some circumstances the influence of the East and of Europe, of the peoples of Russia on the Tatar cuisine is keenly aware now. However, built up over centuries in the struggle with the natural conditions the national dish continue to maintain its uniqueness and stand on the protection of the health of the people, as an example of a healthy diet, resisting an harmful external environmental influence on human.

\section{References}

Bayazitova, F.S. (2007). Vocabulary of food and folk traditions. Kazan: Printing House.

Denmukhametova, I.N. and Yusupova A.Sh. (2011). Synonyms in the speech of Tatar diaspora in China. The Family in the Modern World (pp. 60-63). Helsinki: Unigrafia Oy.

Fatkhullova, K.S., Zamaletdinov R.R. and Yusupova A.Sh. (2013). Information-Communicative Devices for Tatar Language Teaching. World Applied Sciences Journal, 26 (1) (103-107), 1818-4952.

Isanbet, N.S. (2010). Tatar folk proverbs. The second edition. In 3 Vols. Volume 2. Kazan: Tatars. knizh. Publishing House.

Fuchs, K. (1991). Kazan Tatars in the statistical and ethnographical relations. Kazan, 1844; A brief history of the Kazan city. Kazan, 1905. Kazan.

Khairutdinova, T. (1993). Food names in the Tatar language. Kazan.

Mugtasimova, G.R. (2005). Vocabulary of Tatar folk proverbs (obsolete words, dialect and Russian-European borrowings). Kazan: Publishing house of KSU.

Mukhamedova, R.G. Mishar-Tatars. The food and utensils. old-cookery.livejournal.com> 389446.html

Nasiri, K. (2005). Selected. In 4 Vols. Volume 3. Kazan: Tatars. knizh. Publishing House.

Nurmuhametova, R.S. (2013). Development of culinary lexicon of the Tatar language in the $20^{\text {th }}$ century and the beginning of the 21st century. Literature and Culture = Philology and Culture, 4 (34) (86-91), 2074-0239.

Nurmuhametova, R.S. (2014). The impact of the environment on the formation and functioning of food vocabulary of Tatar Philology and Culture. Literature and Culture = Philology and Culture, 4 (38) (164-169), 2074-0239.

Nurmuhametova, R.S. and Sattarova, M.R. (2013). Reflection in the language of spiritual and material culture of the Tatars (based on the vocabulary related to food culture). Science and education in the 21 st century (pp. 121-123). Tambov: Univ. Press.

Nurmukhametova, R.S., Sattarova, M.R. and Zamaletdinov R.R. (2014). The vocabulary of Tatar literary language (the first half of the XX century). Life Science Journal, 11(10), 670-673. http://www.lifesciencesite.com/lsj/life1110/103_25509life111014_670_673. pdf

Tarasova, F.Kh. (2012). Proverbs with component 'food' in the Tatar, Russian and English languages: linguistic and cultural and cognitive-pragmatic aspects. Kazan: RIP.

Yusupova, A.S., Denmukhametova, I.N., Nabiullina, G.A. and Mugtasimova, G.R. (2013) Features of the Language of Tatars Living in China. Middle-East Journal of Scientific Research, 17 (2), 168-172. http://www.idosi.org/mejsr/mejsr17(2)13/7.pdf

Yusupova, A.Sh. (2008). Bilingual lexicography of the Tatar language of the $19^{\text {th }}$ century. Kazan: Publishing House of Kazan.

Yusupova, A.Sh. (2014). Tatar language dictionaries of XIX century as a unified historical and cultural phenomenon. World Applied Sciences Journal, 30 (2), 186-190. http://www.idosi.org/wasj/wasj30(2)14/10.pdf

Zamaletdinov, R.R. (2009). Theoretical and applied aspects of the Tatar cultural linguistics. Kazan: Magarif.

Zamaletdinov, R.R., Nurmuhametova, R.S. (2012). The material culture of the Tatar language in dictionaries of $20^{\text {th }}$ and $21^{\text {st }}$ centuries (on food lexicon). Literature and Culture = Philology and Culture, 3 (29) (51-55), 2074-0239.

Zamaletdinov, R.R. and Nurmuhametova, R.S. (2012) Ethnic and cultural dictionary of the Tatarlanuage: material culture vocabulary (dictionary-directory). Kazan: Fatherland. 